\title{
ChemComm
}

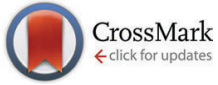

Cite this: Chem. Commun., 2015, 51, 9169

Received 16th April 2015, Accepted 23rd April 2015

DOI: $10.1039 / \mathrm{c} 5 \mathrm{cc} 03180 \mathrm{j}$

www.rsc.org/chemcomm

\section{An integrin-targeted photoactivatable Pt(Iv) complex as a selective anticancer pro-drug: synthesis and photoactivation studies $\dagger$}

\author{
Albert Gandioso, ${ }^{a}$ Evyenia Shaili, ${ }^{\mathrm{b}}$ Anna Massaguer, ${ }^{\mathrm{c}}$ Gerard Artigas, ${ }^{a}$ \\ Alejandro González-Cantó, ${ }^{a}$ Julie A. Woods, ${ }^{d}$ Peter J. Sadler ${ }^{b}$ and \\ Vicente Marchán*a
}

A new anticancer agent based on the conjugation of a photoactivatable Pt(IV) pro-drug to a cyclic RGD-containing peptide is described. Upon visible light irradiation, phototoxicity was induced preferentially in SK-MEL-28 melanoma cancer cells overexpressing $\alpha_{\mathrm{V}} \beta_{3}$ integrin compared to control DU-145 human prostate carcinoma cells.

The use of visible light has enormous potential in chemotherapy for controlling, at a desired time, the place and dose, and release of cytotoxic species from inert anticancer pro-drugs. For this reason, much effort has been dedicated to the development of photoactivatable metal-based anticancer complexes for improving drug efficacy and reducing toxic side-effects associated with platinum-based chemotherapeutic drugs currently used in clinics. ${ }^{1}$ In addition, photoactivation offers the possibility for new mechanisms of action as well as the formation of novel adducts with the final biological target (not only DNA, but also RNA or proteins), which are important variables to overcome inherent or acquired resistance to cisplatin. Among photoactivated metallodrugs, Pt(Iv) diazidodihydroxido complexes are particularly promising since they are inert and nontoxic in the dark, but become highly active against a range of cancer cell lines upon irradiation with visible light, including cisplatin-resistant cells (A2780cis). ${ }^{2}$ Such Pt(Iv) pro-drugs accumulate in tumour cells and bind strongly to DNA by generating adducts distinct from those of cisplatin. ${ }^{3} \mathrm{Ru}(\mathrm{II})$ arene complexes such as $\left[\left(\eta^{6}-p\right.\right.$-cym)$\mathrm{Ru}(\mathrm{bpm})(\mathrm{py})]^{2+}$ or its peptide derivatives can also be activated by visible light to induce the dissociation of the $\mathrm{Ru}$-pyridine bond and the generation of an active species with capacity to react with DNA. ${ }^{4}$ A similar pro-drug approach has been described with some

\footnotetext{
${ }^{a}$ Departament de Química Orgànica and IBUB, Universitat de Barcelona, Barcelona, E-08028, Spain. E-mail: vmarchan@ub.edu

${ }^{b}$ Department of Chemistry, University of Warwick, Warwick, CV4 7AL, Coventry, UK

${ }^{c}$ Departament de Biologia, Universitat de Girona, Campus Montilivi, Girona, E-17071, Spain

${ }^{d}$ Photobiology Unit, Department of Dermatology, Ninewells Hospital, Dundee, DD1 9SY, UK

$\dagger$ Electronic supplementary information (ESI) available: Experimental procedures, characterization data for conjugate 3 , and results from photoactivation studies. See DOI: $10.1039 / \mathrm{c} 5 \mathrm{cc} 03180 \mathrm{j}$
}

$\mathrm{Ru}$ polypyridyl complexes masked with thioether groups that can be removed selectively upon visible light irradiation. ${ }^{5}$ Very recently, caging groups have also been applied to control the activity of $\mathrm{Ru}(\mathrm{II})$ and $\mathrm{Re}(\mathrm{I})$ complexes. ${ }^{6}$

Despite these promising examples, it is desirable to improve some of the pharmacological properties of photoactivatable metallodrugs, such as aqueous solubility and cell uptake, as well as higher selectivity against cancer cells. In this context, targeted approaches based on peptide vectors whose receptors are overexpressed on cancer cells in combination with light activation can be used to develop anticancer agents with a dual mechanism of selectivity, such as the conjugates between a photoactivatable $\mathrm{Ru}(\mathrm{II})$ arene complex and receptor-binding peptides recently described by us ${ }^{4 b}$ or a conjugate between a caged $\operatorname{Re}(\mathrm{I})$ organometallic complex and bombesin. ${ }^{6 b}$

Herein we report the conjugation of a photoactivatable Pt(Iv) pro-drug, trans,trans,trans $\left[\mathrm{Pt}\left(\mathrm{N}_{3}\right)_{2}(\mathrm{OH})_{2}(\mathrm{py})_{2}\right](\mathbf{1})^{2}$ (Fig. 1), to a cyclic peptide containing the RGD sequence (-Arg-Gly-Asp-), which is selectively recognized by $\alpha_{v} \beta_{3}$ and $\alpha_{v} \beta_{5}$ integrins. The overexpression of these transmembrane heterodimeric glycoproteins in different tumor cells together with their known relationship with tumor angiogenesis, which is an essential process for tumor growth and metastasis, makes them relevant targets in medicinal chemistry. ${ }^{7}$ In fact, RGD-containing peptides have been exploited extensively for tumour imaging and for targeted drug delivery of cytotoxic compounds, ${ }^{8}$ including some metal-based anticancer drugs. ${ }^{4 b, 9}$ As recently found by us for conjugates between a $\mathrm{Pt}(\mathrm{Iv})$ derivative of picoplatin and RGD-containing peptides, ${ }^{9 d}$ we hypothesize

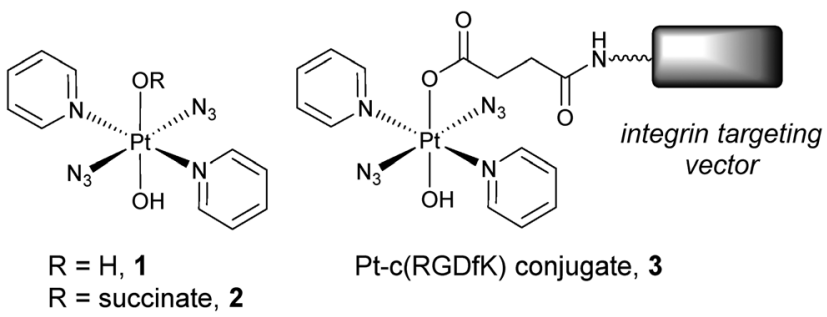

Fig. 1 Structure of trans, trans, trans- $\left[\mathrm{Pt}\left(\mathrm{N}_{3}\right)_{2}(\mathrm{OH})_{2}(\mathrm{py})_{2}\right](\mathbf{1})$, trans, trans, trans$\left[\mathrm{Pt}\left(\mathrm{N}_{3}\right)_{2}(\mathrm{OH})(\mathrm{succ})(\mathrm{py})_{2}\right]$ (2) and the schematic representation of the $\mathrm{Pt}-\mathrm{c}(\mathrm{RGDfK})$ conjugate (3). 
that the peptide vector will confer complex 1 with selectivity for cancer cells overexpressing pro-angiogenic integrins such as $\alpha_{\mathrm{V}} \beta_{3}$ and $\alpha_{V} \beta_{5}$. The novelty of this approach resides in the use of a photoactivatable $\mathrm{Pt}(\mathrm{Iv})$ pro-drug since irradiation with visible light directly within the tumour will trigger the release of cytotoxic Pt(II) species from the internalized conjugate ( 3 in Fig. 1), thus providing a $\mathrm{Pt}(\mathrm{Iv})$-based anticancer agent with dual control over selectivity.

First, one of the axial hydroxyl groups of complex 1 was esterified with succinic anhydride to generate trans,trans,trans$\left[\mathrm{Pt}\left(\mathrm{N}_{3}\right)_{2}(\mathrm{OH})(\mathrm{succ})(\mathrm{py})_{2}\right]$ (2) (Fig. 1), ${ }^{10}$ which contains a carboxylic acid function suitable for attaching the peptide moiety. As shown in Fig. 2, we selected as a carrier the cyclic pentapeptide c(RGDfK), ${ }^{11}$ which is a conjugatable version of Cilengitide, c(RGDf[N-Me]V), an antagonist of pro-angiogenic integrins, and currently in clinical phase III trials for the treatment of patients with brain tumors. ${ }^{12}$ The incorporation of non-natural D-Phe and $[\mathrm{N}-\mathrm{Me}]-\mathrm{Val}$ in the cyclic structure is responsible for increasing both the stability in biological fluids and the higher selectivity for $\alpha_{\mathrm{V}} \beta_{3}$ integrin over $\alpha_{\mathrm{V}} \beta_{5}$ and $\alpha_{5} \beta_{1} \cdot{ }^{12 b}$ In our case, replacement of $N$-methyl Val by Lys allowed further derivatization of the RGD-containing peptide with a polyethyleneglycol spacer at the $\varepsilon-\mathrm{NH}_{2}$ function. Then, complex 2 was attached to peptide intermediate $4^{9 d}$ by using HATU in the presence of DIPEA in anhydrous DMF for $2 \mathrm{~h}$ at RT in the dark. The expected Pt-c(RGDfK) conjugate (3) was obtained as a pale yellow solid (54\% yield) after purification by reversed-phase HPLC and lyophilisation (Fig. S1, ESI $\dagger$ ). Conjugate 3 was unambiguously characterized by high-resolution ESI mass spectrometry and ${ }^{1} \mathrm{H}$ NMR spectroscopy. As shown in Fig. 3 and Fig. S2 (ESI $\dagger$ ), an $m / z$ value consistent with the calculated value of the charged species $\left([\mathrm{M}+\mathrm{H}]^{+}\right)$and with the expected isotopic mass distribution pattern of Pt was obtained. In addition, diagnostic signals from the platinum complex (pyridine ligands) and from the peptide moiety (amide $\mathrm{NH}$ protons and aromatic protons of $\mathrm{D}$-Phe) in the aromatic region of the ${ }^{1} \mathrm{H}$ NMR spectra confirmed the covalent attachment of the Pt complex to the peptide vector (Fig. 3 and Fig. S3, ESI $\dagger$ ).

Next, the efficiency of the photoactivation of Pt-c(RGDfK) conjugate (3) in the presence of $5^{\prime}$-GMP ( 2 mol equiv.) was investigated by HPLC-MS. As shown in Fig. S4 (ESI $\dagger)$, irradiation $\left(\lambda_{\text {irr }}=420 \mathrm{~nm}\right.$,

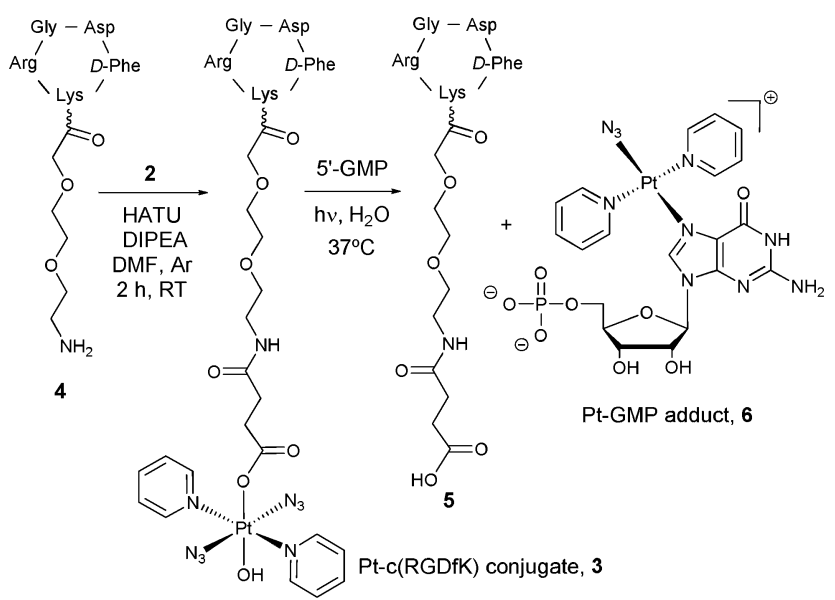

Fig. 2 Schematic representation of the synthesis of the Pt-c(RGDfK) conjugate (3) and of the photo-reaction with 5'-GMP.

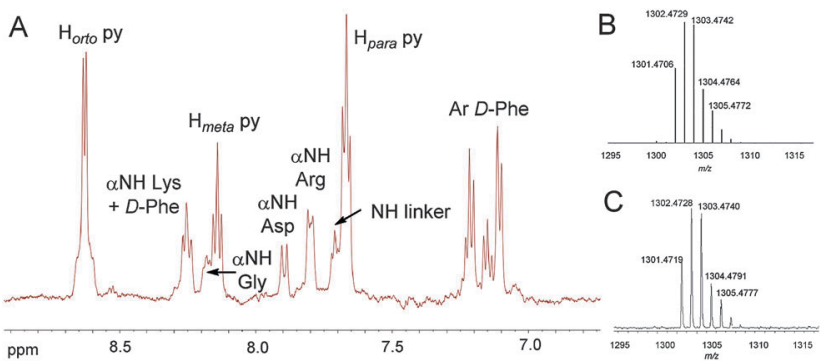

Fig. $3{ }^{1} \mathrm{H}$ NMR spectra of conjugate $3(\mathrm{~A})$ in $\mathrm{H}_{2} \mathrm{O} / \mathrm{D}_{2} \mathrm{O} 9$ : 1 , showing the region between 6.7 and $9.1 \mathrm{ppm}$. Expanded HR ESI mass spectrum of the molecular peak of $\mathbf{3}\left([\mathrm{M}+\mathrm{H}]^{+}\right)$, calculated (B) and experimental (C).

$11 \mathrm{~mW} \mathrm{~cm}{ }^{-2}$, $45 \mathrm{~min}, 37^{\circ} \mathrm{C}$ ) led to the complete disappearance of 3 and to the formation of a major species that was characterized by HR-ESI-MS as the Pt(II)-GMP adduct, trans-[Pt( $\left.\left.\mathrm{N}_{3}\right)\left(5^{\prime}-\mathrm{GMP}\right)(\mathrm{py})_{2}\right]^{+}$ (6 in Fig. 2) (GMP is considered neutral in all the formulae). In addition, two minor GMP adducts were identified, trans$\left[\mathrm{Pt}(\mathrm{py})_{2}\left(5^{\prime}-\mathrm{GMP}\right)_{2}\right]^{2+}$ and $\left[\mathrm{Pt}_{2}\left(\mathrm{~N}_{3}\right)(\mathrm{py})_{4}\left(5^{\prime}-\mathrm{GMP}\right)\right]^{+}$. The photodissociation of conjugate 3 to form the Pt(II)-GMP adduct as a major product, parallels the behaviour observed for the parent complexes $1^{2 a}$ and $2,{ }^{10}$ indicating that the attached peptide does not alter the photochemical properties or the type of photoadducts with a model nucleobase. Furthermore, the release of the intact succinate-c(RGDfK) moiety (5 in Fig. 2) implies that the carrier ligand neither competes with 5 '-GMP for binding to the photoreleased Pt(II) species, nor does it form any secondary reactions, being a simple targeting vector of the Pt(rv) pro-drug.

Having established the photoactivation properties of the Pt-c(RGDfK) conjugate, our next objective was to investigate its toxicity towards different cancer cell lines in the presence of visible light to assess the capacity of the peptide vector to deliver the photoactivatable $\mathrm{Pt}(\mathrm{Iv})$ pro-drug into cancer cells overexpressing integrin receptors. On the basis of flow cytometry studies (Fig. 4), we selected SK-MEL-28 human malignant melanoma cell line as a model to evaluate the phototoxicity of 3 since it expresses high levels of $\alpha_{v} \beta_{3}$ integrin

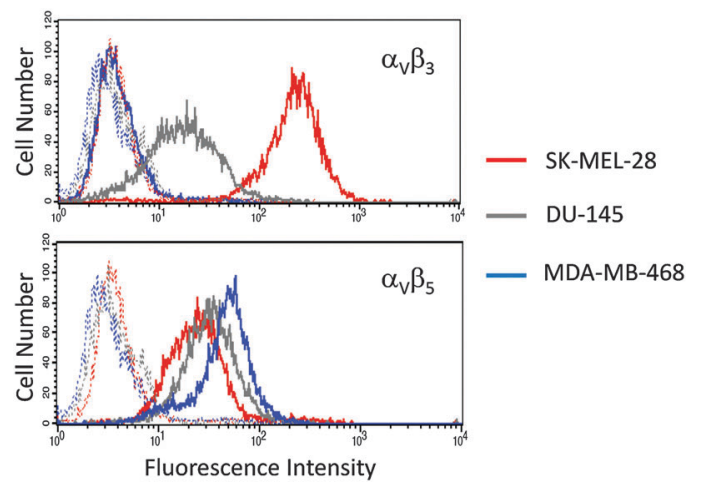

Fig. 4 Expression of $\alpha_{v} \beta_{3}$ and $\alpha_{v} \beta_{5}$ integrins in SK-MEL-28, DU-145 and MDAMB-468 cell lines. Representative flow cytometry histograms obtained after the indirect immunofluorescence staining. Solid lines represent the fluorescence intensity of the cells after the incubation with monoclonal antibodies against both integrins followed by incubation with secondary antibody conjugated to Alexa-Fluor 488. Dotted lines indicate the background staining with the secondary antibody alone. 
compared with $\alpha_{\mathrm{V}} \beta_{5}$ integrin (mean cell fluorescence intensity of 217.4 and 23.3 for $\alpha_{V} \beta_{3}$ and $\alpha_{v} \beta_{5}$ integrins, respectively). ${ }^{9 d}$ As negative control, the DU-145 human prostate carcinoma cell line was selected since the expression of $\alpha_{v} \beta_{3}$ integrin was considerably lower, whereas that of $\alpha_{\mathrm{V}} \beta_{5}$ integrin was similar (mean cell fluorescence intensity of 16.6 and 31.8 for $\alpha_{v} \beta_{3}$ and $\alpha_{v} \beta_{5}$ integrins, respectively). As expected, the internalization of the fluorescein-labelled RGD-containing peptide, Fluo-c(RGDfK) (7), ${ }^{9 d}$ was slightly higher in the $\alpha_{v} \beta_{3}$ integrin overexpressing SK-MEL-28 cells than in DU-145 (by 1.6-fold when incubated at $10 \mu \mathrm{M}$; see Fig. S5, ESI $\dagger$ ), which points to the active participation of this integrin receptor in the uptake of the peptide.

The photocytotoxicity of the Pt-c(RGDfK) conjugate (3) and of the parent Pt complexes (1 and 2) was determined upon irradiation with visible light $\left(\lambda_{\text {irr }}=420 \mathrm{~nm}, 5 \mathrm{~J} \mathrm{~cm}^{-2}\right)$ in both cell lines. The photoactivated dose-dependent inhibition of cell viability for compounds 1-3 towards SK-MEL-28 and DU-145 cells and their phototoxic indices are summarised in Table 1 and the cytotoxicity plots are shown in Fig. S6 (ESI $\dagger$ ). First, it is worth noting that the $\mathrm{IC}_{50}$ value for complex 1 in SK-MEL-28 was similar to those previously found in other cancer cell lines $\left(\mathrm{IC}_{50}=6.8 \mu \mathrm{M}\right.$ in HaCaT, $8.3 \mu \mathrm{M}$ in $\mathrm{A} 2780$ or $8.4 \mu \mathrm{M}$ in OE19, under blue light irradiation), ${ }^{2 b}$ although the cytotoxicity in DU-145 cells was about 4-fold lower than in the melanoma cancer cell line. Hence, these results confirm the high antitumour efficiency of the Pt(Iv) pro-drug against cancer cells of different origin when photoactivated with visible light. Second, the cytotoxic effect of 1 was slightly reduced in SK-MEL-28 (about 1.5-fold) upon derivatization with a succinate group (2). This tendency was not reproduced in DU-145, since the cytotoxic effect was increased upon succinylation $\left(\mathrm{IC}_{50}=20 \mu \mathrm{M}\right.$ for $2 v s . \mathrm{IC}_{50}=43 \mu \mathrm{M}$ for $\left.\mathbf{1}\right)$.

As shown in Table 1, the phototoxicity of conjugate 3 in SK-MEL-28 $\left(\mathrm{IC}_{50}=19.5 \mu \mathrm{M}\right)$ was similar to that of the parent succinylated complex $2\left(\mathrm{IC}_{50}=15.5 \mu \mathrm{M}\right)$, whereas the differences in the irradiated mean $\mathrm{IC}_{50}$ values were higher in DU-145 cells $\left(\mathrm{IC}_{50}=20 \mu \mathrm{M}\right.$ for 2 and $54 \mu \mathrm{M}$ for 3 ). This result is in good agreement with the levels of expression of the $\alpha_{V} \beta_{3}$ integrin and with the cellular uptake experiments with the fluorescein-labelled peptide, and is consistent with the participation of the receptor in the biological activity of the conjugate. Hence, conjugation to the RGD-containing peptide vector seems to confer selectivity to complex 2 since the anticancer activity is higher in the melanoma cancer cell line that overexpresses $\alpha_{\mathrm{V}} \beta_{3}$ integrin receptor whereas a lower phototoxicity was found in the human prostate cancer cell line. This difference was increased when conjugate 3 was irradiated with UVA $\left(\lambda_{\text {irr }}=365 \mathrm{~nm}, 5 \mathrm{~J} \mathrm{~cm}^{-2}\right)$ in both cell lines.

Table $1 \quad I_{50}$ values of $5 \mathrm{~J} \mathrm{~cm}^{-2}$ visible light or UVA irradiated human DU-145 and SK-MEL-28 cells pretreated with compounds 1-3

\begin{tabular}{|c|c|c|c|c|c|c|c|}
\hline \multirow[b]{3}{*}{1} & \multirow[b]{3}{*}{$420 \mathrm{~nm}$} & \multicolumn{3}{|c|}{ SK-MEL-28 } & \multicolumn{3}{|c|}{ DU-145 } \\
\hline & & \multicolumn{2}{|c|}{$\mathrm{IC}_{50}{ }^{a}(\mu \mathrm{M})$} & \multirow{2}{*}{$\frac{\mathrm{PI}^{b}}{20.8}$} & \multicolumn{2}{|c|}{$\mathrm{IC}_{50}{ }^{a}(\mu \mathrm{M})$} & \multirow{2}{*}{$\frac{\mathrm{PI}^{b}}{4.9}$} \\
\hline & & 10.2 & $(7.9-13.0)$ & & 43.2 & $(33.0-56.6)$ & \\
\hline 2 & $420 \mathrm{~nm}$ & 15.5 & $(10.2-23.6)$ & 11.3 & 20.0 & $(14.7-27.3)$ & 8.8 \\
\hline 3 & $420 \mathrm{~nm}$ & 19.5 & $(13.4-28.2)$ & 3.6 & 53.9 & Wide & 1.3 \\
\hline 3 & $365 \mathrm{~nm}$ & 9.9 & $(9.5-10.1)$ & 8 & 56.4 & (50.9-61.9) & 2.7 \\
\hline
\end{tabular}

${ }^{a} \mathrm{IC}_{50}$ is defined as the concentration of compound that inhibits dye uptake by $50 \%$. The lowest value indicates the highest toxicity to cells. ${ }^{b}$ PI: phototoxic index.
Interestingly, DU-145 cells treated with aminolevulinic acid (ALA) using the same blue light source were twice more susceptible than SK-MEL-28 cells (irradiated mean $\mathrm{IC}_{50}$ values $=0.12 \mathrm{mM}$ and $0.23 \mathrm{mM}$, respectively). Thus, the melanoma cancer cells were more resistant to the porphyrin-based therapy, but more sensitive to the Pt-based therapy compared to the prostate cancer cells.

Since the cellular uptake of the Pt-peptide conjugate depends both on the level of expression of the pro-angiogenic integrins and on the binding affinity of the RGD-containing peptide towards these receptors, the determination of the intracellular accumulation is of high importance to assess the effect of the peptide conjugation on the biological activity of the Pt(Iv) pro-drug as well as to investigate the contribution of each integrin subtype. For this purpose, in addition to SK-MEL-28 and DU-145 cells, we selected the MBA-MD-468 breast adenocarcinoma cell line as positive control for $\alpha_{\mathrm{V}} \beta_{5}$ integrin. As shown in Fig. 4, the expression of $\alpha_{V} \beta_{5}$ integrin was considerably higher than that of $\alpha_{V} \beta_{3}$ integrin (mean cell fluorescence intensity of 3.8 and 42.4 for $\alpha_{V} \beta_{3}$ and $\alpha_{V} \beta_{5}$ integrins, respectively). Then, the three cancer cell lines were exposed to $10 \mu \mathrm{M}$ solutions of 1-3 in the dark for $1 \mathrm{~h}$, and the intracellular level of platinum was quantified by inductivelycoupled plasma mass spectrometry (ICP-MS).

As shown in Fig. 5, the accumulation of platinum after exposure of the three cell lines to $\mathrm{Pt}-\mathrm{c}(\mathrm{RGDfK})$ conjugate (3) $\left(46.6 \pm 2\right.$ pmol Pt per $10^{6}$ cells in DU-145, $130.7 \pm 9$ pmol Pt per $10^{6}$ cells in SK-MEL-28 and $166.5 \pm 6$ pmol Pt per $10^{6}$ cells in MBA-MD-468) was higher than that of complex 1 (26.2 \pm 2.4 pmol Pt per $10^{6}$ cells in DU-145, $72.6 \pm 1.9$ pmol Pt per $10^{6}$ cells in SK-MEL-28 and $73.6 \pm 2$ pmol Pt per $10^{6}$ cells in MBA-MD-468) or $2\left(15.9 \pm 2.7\right.$ pmol Pt per $10^{6}$ cells in DU-145, $75.4 \pm 9.6$ pmol Pt per $10^{6}$ cells in SK-MEL-28 and $86.8 \pm$ 7 pmol Pt per $10^{6}$ cells in MBA-MD-468). This clearly indicates that peptide conjugation has a positive effect on the intracellular accumulation of the photoactivatable Pt(Iv) pro-drug. Notably, platinum accumulation in SK-MEL-28 cells after exposure to conjugate 3 was higher (about 2.8-fold) than in DU-145 cells, which agree with the higher expression of $\alpha_{v} \beta_{3}$ integrin in the human malignant melanoma cell line compared with the prostate carcinoma cell line, as well as with the internalization studies with the fluorescein-labelled peptide.

To our surprise, the intracellular accumulation of 3 in MBAMD-468 was also higher than in DU-145 cells (about 3.6-fold) despite

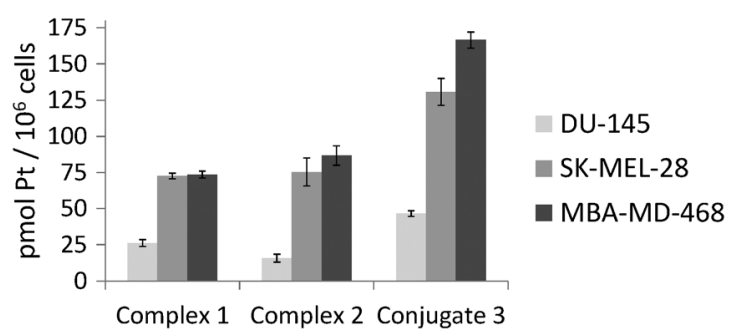

Fig. 5 Cell accumulation of platinum in SK-MEL-28, DU-145 and MBAMD-468 cells after exposure to compounds 1-3 (10 $\mu \mathrm{M}$, dark, $1 \mathrm{~h})$. The platinum content is related to the cell number. Errors bars represent the standard deviation of three replicates. 
the very low expression of $\alpha_{v} \beta_{3}$ integrin in the breast carcinoma cell line. These results and the fact that accumulation of 3 in MBA-MD468 was about 1.3-fold higher than in SK-MEL-28 points out to the internalization of the Pt-c(RGDfK) conjugate mediated by $\alpha_{\mathrm{V}} \beta_{5}$ integrin as well. These results are in agreement with the known selectivity of RGD-containing peptides, particularly the cyclic version $\mathrm{c}(\mathrm{RGDfK})$, for cancer cells overexpressing $\alpha_{\mathrm{V}} \beta_{3}$ and $\alpha_{\mathrm{V}} \beta_{5}$ integrins and suggest in all cases the participation of the peptide in the internalization of the conjugate. The reduced selectivity of conjugate 3 for $\alpha_{\mathrm{V}} \beta_{3}$ integrin compared with Cilengitide can be attributed to the replacement of $[\mathrm{N}-\mathrm{Me}]-\mathrm{Val}$ by the Lys residue where the photoactivatable Pt(Iv) complex is attached. Hence, on the basis of the overall results, we can envisage the integrin-mediated internalization and accumulation of the intact Pt-peptide conjugate in cancer cells overexpressing $\alpha_{V} \beta_{3}$ and/or $\alpha_{V} \beta_{5}$ integrins, where it will be photoactivated to generate cytotoxic $\mathrm{Pt}$ (II) species with a capacity to react with nucleic acids, as inferred by the adduct generated with $5^{\prime}$-GMP. Otherwise, a premature activation of the Pt(Iv) pro-drug or hydrolysis of the conjugate would lead to similar or even lower Pt accumulation ratios than those obtained with control complexes. Interestingly, a correlation was found between intracellular accumulation of conjugate 3 and phototoxicity (see Table 1 ): a lower $\mathrm{IC}_{50}$ value upon visible light irradiation and a higher phototoxic index was found in the melanoma cancer cells that accumulated a higher amount of the compound compared with prostate carcinoma cells. Notably, the accumulation of 1 and 2 in SK-MEL-28 and MBA-MD-468 cells was also higher than in DU-145, thereby revealing a preference for the melanoma and breast cancer cells. It is also interesting that despite the higher accumulation of conjugate 3 compared with the parent complexes, the phototoxicity was slightly reduced, particularly when compared with 1 in SK-MEL-28. This might be attributable to differences in the quantum yield of the compounds and to the accumulation of the conjugate in intracellular vesicles that might interfere with the interaction of the released $\mathrm{Pt}(\mathrm{II})$ species with the target.

In conclusion, our results demonstrate the potential of conjugating photoactivatable metal complexes, such as $\mathrm{Pt}(\mathrm{Iv})$ pro-drugs, to peptides with the aim of generating receptortargeted metal-based anticancer drugs with reduced toxic side effects based on dual control over selectivity. The fact that the Pt-c(RGDfK) conjugate can also be internalized by $\alpha_{V} \beta_{5}$ integrin opens up the door to delivering such promising anticancer metallodrugs to tumours overexpressing $\alpha_{V} \beta_{5}$ integrin $^{13}$ or to tumours coexpressing both $\alpha_{V} \beta_{3}$ and $\alpha_{V} \beta_{5}$ integrins. ${ }^{7 b, 14}$ Such a multiintegrin targeting approach would provide new metal-based anticancer strategies and so benefit a wider range of patients by increasing the number of tumours which can be targeted. ${ }^{15}$

This work was supported by funds from the Spanish Ministerio de Ciencia e Innovación (grants CTQ2010-21567-C02-01-02, CTQ201452658-R and the RNAREG project, grant CSD2009-00080), the Generalitat de Catalunya (2009SGR-208 and XRB), the ERC (grant 247450), EPSRC (EP/F034210/1) and EPSRC (MOAC Doctoral Training Centre, EP/F500378/1). The authors acknowledge helpful assistance of Dr Irene Fernández and Laura Ortiz (MS), Dr Maite Romero (ICP-MS) and Dr M. Antònia Molins (NMR) from CCiTUB.

\section{Notes and references}

1 (a) C. Moucheron, New J. Chem., 2009, 33, 235; (b) D. Crespy, K. Landfester, U. S. Schubert and A. Schiller, Chem. Commun., 2010, 46, 6651; (c) N. A. Smith and P. J. Sadler, Philos. Trans. R. Soc., A, 2013, 371, 20120519, DOI: 10.1098/rsta.2012.0519.

2 (a) N. J. Farrer, J. A. Woods, L. Salassa, Y. Zhao, K. S. Robinson, G. Clarkson, F. S. Mackay and P. J. Sadler, Angew. Chem., Int. Ed., 2010, 49, 8905; (b) Y. Zhao, J. A. Woods, N. J. Farrer, K. S. Robinson, J. Pracharova, J. Kasparkova, O. Novakova, H. Li, L. Salassa, A. M. Pizarro, G. J. Clarkson, L. Song, V. Brabec and P. J. Sadler, Chem. - Eur. J., 2013, 19, 9578; (c) A. M. Pizarro, R. J. McQuitty, F. S. Mackay, Y. Zhao, J. A. Woods and P. J. Sadler, ChemMedChem, 2014, 9, 1169.

3 (a) J. Pracharova, L. Zerzankova, J. Stepankova, O. Novakova, N. J. Farrer, P. J. Sadler, V. Brabec and J. Kasparkova, Chem. Res. Toxicol., 2012, 25, 1099; (b) H.-C. Tai, R. Brodbeck, J. Kasparkova, N. J. Farrer, V. Brabec, P. J. Sadler and R. J. Deeth, Inorg. Chem., 2012, 51, 6830.

4 (a) S. Betanzos-Lara, L. Salassa, A. Habtemanriam and P. J. Sadler, Chem. Commun., 2009, 6622; (b) F. Barragán, P. López-Senín, L. Salassa, S. Betanzos-Lara, A. Habtemariam, V. Moreno, P. J. Sadler and V. Marchán, J. Am. Chem. Soc., 2011, 133, 14098.

5 (a) R. E. Goldbach, I. Rodriguez-Garcia, J. H. van Lenthe, M. A. Siegler and S. Bonnet, Chem. - Eur. J., 2011, 17, 9924; (b) A. Bahreman, B. Limburg, M. A. Siegler, E. Bouwman and S. Bonnet, Inorg. Chem., 2013, 52, 9456; (c) S. H. C. Askes, A. Bahreman and S. Bonnet, Angew. Chem., Int. Ed., 2014, 53, 1029.

6 (a) T. Joshi, V. Pierroz, C. Mari, L. Gemperle, S. Ferrari and G. Gasser, Angew. Chem., Int. Ed., 2014, 53, 2960; (b) A. Leonidova, V. Pierroz, R. Rubbiani, Y. Lan, A. G. Schmitz, A. Kaech, R. K. O. Sigel, S. Ferrari and G. Gasser, Chem. Sci., 2014, 5, 4044.

7 (a) M. Friedlander, P. C. Brooks, R. W. Shaffer, C. M. Kincaid, J. A. Varner and D. A. Cheresh, Science, 1995, 270, 1500; (b) J. S. Desgrosellier and D. A. Cheresh, Nat. Rev. Cancer, 2010, 10, 9; (c) L. Auzzas, F. Zanardi, L. Battistini, P. Burreddu, P. Carta, G. Rassu, C. Curti and G. Casiraghi, Curr. Med. Chem., 2010, 17, 1255; (d) D. G. Stupack and D. A. Cheresh, Curr. Top. Dev. Biol., 2004, 64, 207.

8 (a) K. Temming, R. M. Schiffelers, G. Molema and R. J. Kok, Drug Resist. Updates, 2005, 8, 381; (b) S. Liu, Mol. Pharmaceutics, 2006, 3, 472; (c) F. Danhier, A. Le Breton and V. Préat, Mol. Pharmaceutics, 2012, 9, 2961.

9 (a) S. Mukhopadhyay, C. M. Barnés, A. Haskel, S. M. Short, K. R. Barnes and S. J. Lippard, Bioconjugate Chem., 2008, 19, 39; (b) N. Graf, D. R. Bielenberg, N. Kolishetti, C. Muus, J. Banyard, O. C. Farokhzad and S. J. Lippard, ACS Nano, 2012, 6, 4530; (c) Y. Yuan, R. T. K. Kwok, B. Z. Tang and B. Liu, J. Am. Chem. Soc., 2014, 136, 2546; (d) A. Massaguer, A. González-Cantó, E. Escribano, S. Barrabés, G. Artigas, V. Moreno and V. Marchán, Dalton Trans., 2015, 44, 202.

10 E. Shaili, PhD thesis, University of Warwick, 2013.

11 (a) K.-E. Gottschalk and H. Kessler, Angew. Chem., Int. Ed., 2002, 41, 3767; (b) F. Gaertner, H. Kessler, H. Wester, M. Schwaiger and A. Beer, Eur. J. Nucl. Med. Mol. Imaging, 2012, 39, S126.

12 (a) M. A. Dechantsreiter, E. Planker, B. Mathä, E. Lohof, G. Hölzemann, A. Jonczyk, S. L. Goodman and H. Kessler, J. Med. Chem., 1999, 42, 3033; (b) C. Mas-Moruno, F. Rechenmacher and H. Kessler, Anti-Cancer Agents Med. Chem., 2010, 10, 753.

13 S. L. Goodman, H. J. Grote and C. Wilm, Biol. Open, 2012, 1, 329.

14 A. Erdreich-Epstein, H. Shimada, S. Groshen, M. Liu, L. S. Metelitsa, K. S. Kim, M. F. Stins, R. C. Seeger and D. L. Durden, Cancer Res., 2000, 60, 712 .

15 H. M. Sheldrake and L. H. Patterson, J. Med. Chem., 2014, 57, 6301. 